\title{
Non-classical forms of pemphigus: pemphigus herpetiformis, IgA pemphigus, paraneoplastic pemphigus and IgG/lgA pemphigus"
}

\author{
Adriana Maria Porro ${ }^{1}$ \\ Laura de Sena Nogueira Maehara ${ }^{3}$
}

\author{
Livia de Vasconcelos Nasser Caetano² \\ Milvia Maria dos Santos Enokihara ${ }^{4}$
}

DOI: http://dx.doi.org/10.1590/abd1806-4841.20142459

Abstract: The pemphigus group comprises the autoimmune intraepidermal blistering diseases classically divided into two major types: pemphigus vulgaris and pemphigus foliaceous. Pemphigus herpetiformis, $\operatorname{IgA}$ pemphigus, paraneoplastic pemphigus and IgG/IgA pemphigus are rarer forms that present some clinical, histological and immunopathological characteristics that are different from the classical types. These are reviewed in this article. Future research may help definitively to locate the position of these forms in the pemphigus group, especially with regard to pemphigus herpetiformis and the IgG/ IgA pemphigus.

Keywords: Pathology; Pemphigus; Skin; Diseases, Vesiculobullous

\section{INTRODUCTION}

Pemphigus is a group of life-threatening autoimmune intraepidermal blistering diseases caused by immunoglobulins directed against keratinocyte cell surface components and histologically characterized by acantholysis. Classically there are two major types of pemphigus: vulgaris (PV) and foliaceous (PF), in which IgG autoantibodies recognize desmossomal components desmoglein-3 (Dsg-3) and desmoglein-1 (Dsg-1) respectively. ${ }^{1-3}$

Since 1975 rare forms of pemphigus have however been described, presenting clinical, histological and immunopathological aspects that differentiate them from the classical vulgaris and foliaceus variants. ${ }^{4}$

This article reviews the current knowledge about these non-classical variants of pemphigus.

\section{PEMPHIGUS HERPETIFORMIS}

Since 1955, before immunological studies were available, there were a number of reports that clinically resembled dermatitis herpetiformis $(\mathrm{DH})$ in patients, but which showed histological features of pemphigus with acantholysis. ${ }^{5-7}$ Other cases were later described, which showed circulating and in vivo bound pemphigus antibodies. ${ }^{8-10}$ In 1975, Jablonska et al. ${ }^{11}$ described a similar case and proposed the name pemphigus herpetiformis $(\mathrm{PH})$. These authors believed that it was a variant of pemphigus having a long course, with early atypical clinical and histological features, that could evolve into typical pemphigus if the patient did not receive appropriate treatment. In 1987, a review of 205 cases of pemphigus found 15 $(7.3 \%)$ cases that were classified as $\mathrm{PH}$, five of which also presented features of PF.12 In 1996 Santi et al. described seven cases of $\mathrm{PH}$ that showed features of $\mathrm{PF}$, or had disease that evolved into classic PF (five), fogo selvagem (FS) (one) and PV (two), and all of them presented antiepidermal autoantibodies that recognized Dsg- $1 .{ }^{13}$ This was the first recognized PH antigen. ${ }^{13-15}$ Later, some reports also found antibodies against Dsg- 3 or both DSg-1 and 3 and, more recently, desmocollin-1(Dsc-1) desmocollin-3 (Dsc-3) and an unknown 178-kDa protein. ${ }^{16-20}$

Received on 19.01.2013.

Approved by the Advisory Board and accepted for publication on 14.02.2013.

* Work performed at the Dermatology Department, Paulista School of Medicine - Federal University of São Paulo (EPM-UNIFESP) - São Paulo (SP), Brazil. Conflict of interest: None

Financial Support: Maehara L de SN received a scholarship from CNPq (201591/2012-0)

Dermatologist. Masters Degree and PhD. Adjunct Professor and Coordinator of Bullous Dermatosis at the Dermatology Department, Paulista School of Medicine - Federal University of São Paulo (EPM-UNIFESP) - São Paulo (SP), Brazil.

Dermatologist with specialization in Bullous Dermatosis at the Dermatology Department, Paulista School of Medicine - Federal University of São Paulo (EPM-UNIFESP) - São Paulo (SP), Brazil.

Dermatologist with specialization in Bullous Dermatosis and Pediatric Dermatology at the Dermatology Department, Paulista School of Medicine - Federal University of São Paulo (EPM-UNIFESP). PhD-candidate at UNIFESP (Translational Medicine) and the University of Groningen (Center for Blistering Diseases, Groningen University Medical Center, Netherlands).

Pathologist. Masters Degree and PhD. Dermatopathologist at the Dermatology and Pathology Departments, Paulista School of Medicine - Federal University of São Paulo (EPM-UNIFESP) - São Paulo (SP), Brazil. 
At present there seems to be some consensus on whether PH is a distinct entity, and most authors consider it to be different from the classic pemphigus variants because of its clinical peculiarity and benign course., ${ }^{418-27}$ However, others have described it as a variant of $\mathrm{PF}$ or $\mathrm{PV}$, given the fact that several patients with $\mathrm{PH}$ show features of or may evolve into having PF or PV, besides frequently presenting the same target cell surface antigens. ${ }^{13,15}$ A recent study that has analyzed the Dsg-1 and Dsg-3 epitopes recognized by serum samples from cases of mucosal dominant-type PV and mucocutaneous-type PV over the disease course, also studied sera from $19 \mathrm{PH}$ patients and 14 PNP cases, finding that PNP and PH show broader epitope distribution compared with the classical pemphigus. ${ }^{25}$ This study concluded that the different autoantibody profiles between these diseases and PV may contribute to their unique clinic and histopathological characteristics.

\section{DEFINITION AND EPIDEMIOLOGY}

$\mathrm{PH}$ is characterized by clinical features that resemble DH and immunological and histological findings consistent with pemphigus. It is a rare pemphigus type, accounting for $6-7 \%$ of cases in some studies, that equally affects men and women, aged 31 to 83 years, with rare case reports during childhood. . $^{21,28-31}$

\section{CLINICAL FEATURES}

Patients with $\mathrm{PH}$ are rarely thought to have this diagnosis when they first seek medical care. Clinical presentation is usually atypical, and other diagnoses can be hypothesized, such as DH, bullous pemphigoid and linear IgA bullous dermatosis. ${ }^{12}$ Patients usually show erythematous, gyrate, annular and edematous lesions, with clusters of small or abortive vesicles and/ or pustules, frequently in herpetiform pattern (Figure 1). ${ }^{11}$ These features are not generally seen in PF and PV. ${ }^{21}$ Mucous lesions are not a frequent issue, but can be present in some patients. Pruritus is frequently associated and might be severe.,11 Some patients can show eosinophilia in the blood. ${ }^{12,32} \mathrm{PH}$ can sometimes evolve into the classical forms of pemphigus (PV and PF). ${ }^{4}$ The opposite has also been described in the literature. ${ }^{11,33}$ Other cases can be initially misdiagnosed as other immunobullous diseases or as the classic variants of pemphigus, such as in one of the four $\mathrm{PH}$ patients of our outpatient clinic, who was initially thought to have PF due to the histopathologic and DIF results (Maehara L de S, et al. unpublished data). This female patient evolved years later with pruritic edematous plaques, with grouped vesicles and tense blisters. The histological exam and DIF revealed interstitial edema, vascular ecstasy and epidermal exocytosis of neutrophils and eosinophils, with intercellular deposits of IgG and C3.
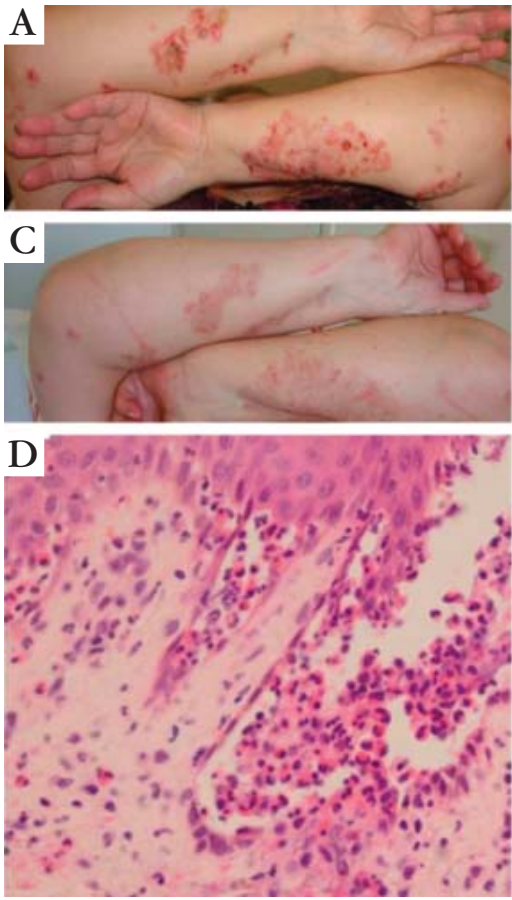
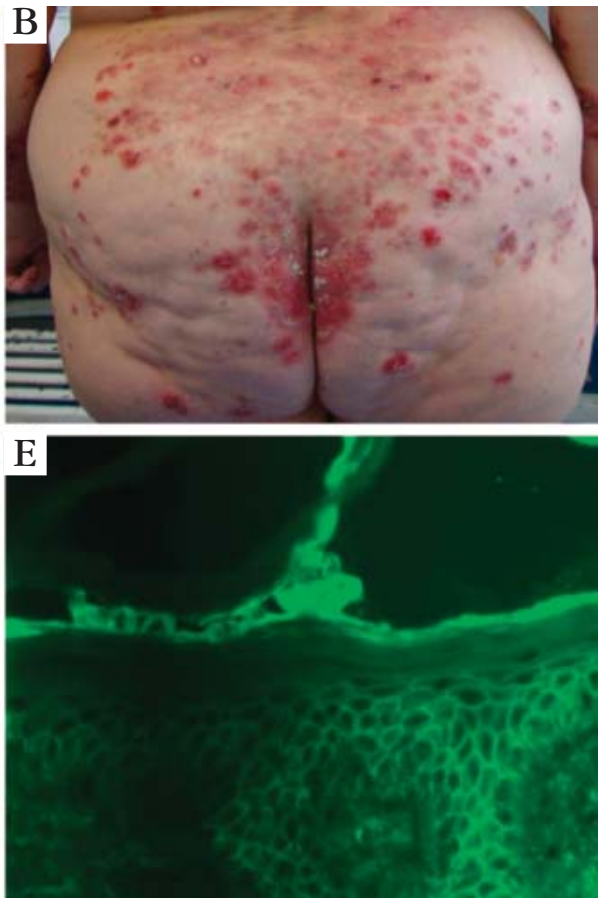

FIGURE 1: Pemphigus herpetiformis: (A) patient presenting grouped vesicles, blisters, erosions and crusts onto an erythematous skin in a herpetiform pattern on her forearms; (B) similar lesions on her buttocks and back; (C) the same patient 10 days after pulse therapy with methylprednisolone $(1 \mathrm{~g} /$ day for 3 days), showing a good clinical response; (D) histopathological exam of a forearm lesion showing suprabasal blister containing some acantholytic cels, neutrophils and eosinophils, besides focal eosinophilic spongiosis (HE 400x); (E) DIF of perilesional skin showing intercellular distribution of IgG and C3 throughout the entire epidermis 


\section{HISTOPATHOLOGY}

The histological findings can vary among patients and one patient can present different histological features at different times or biopsies. More than one biopsy may therefore be necessary for diagnosis of $\mathrm{PH} .{ }^{11,12,34}$ Subcorneal pustules and/ or intraepidermal vesicles filled with neutrophils and /or eosinophils and neutrophilic and/ or eosinophilic spongiosis have already been described in those cases (Figure 1). Acantholysis may be minimal or absent. ${ }^{4,35}$ Although this variant differs histologically from PF and PV due to these characteristic findings, the histologic patterns are widely heterogeneous: ranging from those with only spongiosis and inflammatory cells exocitosis to typical acantholysis.

\section{IMMUNO-PATHOGENESIS}

DIF is the same as the classic forms of pemphigus: intercellular deposits of IgG and C3 in the epidermis (Figure 1). Indirect immunofluorescence (IIF), enzyme-linked immunosorbent assay (ELISA) or immunoblotting can show circulating antibodies against epidermal components, usually Dsg-1, and less commonly Dsg-3, Dsc 1 and 3 and an unknown $178-\mathrm{kDa}$ protein. ${ }^{13-20}$ Although most cases show the same target antigens of the classic variants of pemphigus the consequences of the antibody binding are probably different, as $\mathrm{PH}$ autoantibodies may recognize functionally less important epitopes of Dsg- 1 or 3 and therefore do not lead directly to acantholysis. It is thought that autoantibodies in PH may induce signaling pathway of cytokines (IL-8) production by keratinocytes that attract inflammatory cells to the tissue, with focal intercellular edema and eosinophilic spongiosis. ${ }^{36,37}$ Another recent study may favor this hypothesis since it was found that that $\mathrm{PH}$ sera showed a broader epitope distribution compared with PV, which may contribute to its characteristic clinicohistopathological features. ${ }^{25}$

\section{ASSOCIATIONS}

Some diseases have been described together with $\mathrm{PH}$, such as psoriasis, thyroid diseases, systemic lupus erythematosus, HIV infection and malignancies: lung cancer, esophageal carcinoma, prostatic cancer and cutaneous angiosarcoma. ${ }^{20,22,23,38-46}$ Some authors suggest the name paraneoplasic pemphigus herpetiformis, because of the parallel course of both diseases. However, IIF in rat bladder has not been evaluated by those reports and only two of them searched for the known paraneoplasic pemphigus antigens by immunoblotting. ${ }^{22,45}$

\section{TREATMENT}

PH usually has an indolent course and normal- ly responds well to treatment, with a tendency to complete remission even with low doses of corticosteroids. Dapsone has been used with good results and may be given as monotherapy or in combination with systemic steroids. Immunosuppressants such as azathioprine and cyclophosphamide can also be used, ${ }^{4}$ especially in cases evolving to the classical forms of pemphigus. ${ }^{13}$ The $\mathrm{PH}$ patients of our outpatient dermatological clinic were treated with systemic steroids $(0,5-1,23 \mathrm{mg}$ of prednisone) together with dapsone. One patient, who presented with severe disease at the beginning, required pulse therapy with methylprednisolone ( $1 \mathrm{~g} /$ day for 3 days) together with azathioprine $150 \mathrm{mg} /$ day (Figure 1). However, effective control was achieved only after the introduction of dapsone, and all drugs were then gradually discontinued without recurrence (Maehara Lde S et al., unpublished data).

\section{IGA PEMPHIGUS}

IgA pemphigus was first described by Wallach, Foldes, and Cottenot in 1982 under the name subcorneal pustular dermatosis and monoclonal $\operatorname{IgA} .{ }^{47} \mathrm{It}$ is a group of autoimmune intraepidermal blistering diseases presenting with a vesiculopustular eruption, neutrophil infiltration, acantholysis and tissue-bound and circulating $\operatorname{IgA}$ antibodies targeting desmosomal or nondesmosomal cell surface components in the epidermis. ${ }^{48}$ There are many synonyms for IgA pemphigus: intraepidermal neutrophilic IgA dermatosis, intercellular IgA dermatosis, intercellular IgA vesiculopustular dermatosis, intraepidermal IgA pustulosis, IgA pemphigus foliaceus, and IgA herpetiform pemphigus. ${ }^{47,49-57}$

\section{EPIDEMIOLOGY}

IgA pemphigus is a rare entity among the pemphigus diseases considering that only about 70 cases were reported up to $2010 .^{58}$ Its frequency is currently not defined, and its race distribution is also unknown. The sex distribution of IgA pemphigus reveals a maleto-female ratio of $1: 1.33{ }^{59}$ The age distribution is 1 month to 85 years old. ${ }^{4}$

\section{CLINICAL FEATURES}

The onset of IgA pemphigus is reported to be subacute. ${ }^{59}$ There are two distinct types of IgA pemphigus: the subcorneal pustular dermatosis (SPD) type and the intraepidermal neutrophilic (IEN) type. Patients with both types of IgA pemphigus clinically present with flaccid vesicles or pustules on erythematous or normal skin. The pustules tend to coalesce to form an annular or circinate pattern with crusts in the central area (Figure 2A and B). The SPD type shows clinical features similar to those of SPD. The IEN type demon- 
strates a characteristic clinical feature, the so-called "sunflower-like" configuration. A herpetiform appearance has sometimes also been reported. ${ }^{54}$ The sites of predilection are the axillary and groin areas, but the trunk and proximal extremities are commonly involved. About half of IgA pemphigus patients suffer from pruritus, and mucous membrane involvement is rare. ${ }^{49,53,59,60}$

\section{HISTOPATHOLOGY}

Histopathologic examination of IgA pemphigus shows slight acantholysis and neutrophilic infiltration in the epidermis. Acantholysis in IgA pemphigus is much milder than that seen in classic pemphigus. ${ }^{57}$ In the SPD type of IgA pemphigus, pustules are located subcorneally in the upper epidermis, whereas in the IEN type, suprabasilar pustules in the lower or entire epidermis are present. ${ }^{49,53,61}$

\section{IMMUNO-PATHOGENESIS}

IgA deposition in the intercellular substance of the epidermis is detected in all cases of IgA pemphigus by DIF of perilesional skin, usually in a pattern similar to pemphigus IgG deposition (Figure 2C). ${ }^{49,53-56,60,62}$ IgG or complement component $\mathrm{C} 3$ is also sometimes deposited but is weaker than $\operatorname{IgA} .^{59}$ In the SPD type of $\operatorname{IgA}$ pemphigus, IgA deposition is limited to the upper epidermal cell surfaces, whereas in the IEN type of IgA pemphigus, there is intercellular IgA deposition restricted to the lower epidermis or throughout the entire epidermis. ${ }^{54,60}$ IIF using patient sera and substrates such as healthy human skin or monkey esophagus shows the positive result in the cell-cell contact region in the entire epidermis in about $50 \%$ of patients (Figure 2D). The titers for autoantibodies are lower than that in classic pemphigus. ${ }^{59}$ There are some reports of cases with presence of both $\operatorname{IgA}$ and IgG antibodies, which raises the question of whether pemphigus with both IgG and IgA autoantibodies is a subset of IgA pemphigus or not. ${ }^{63}$ The subclass of in vivo-bound and circulating $\operatorname{IgA}$ autoantibodies has also been determined and is exclusively IgA1. ${ }^{49,55,61}$ Enzyme-linked immunosorbent assay (ELISA) can be used for the diagnosis of IgA pemphigus and for detection of autoantibodies in individual patients. ${ }^{64}$

$\operatorname{IgA}$ pemphigus is a condition in which the $\operatorname{IgA}$ reaction to the keratinocyte cell surfaces is thought to be the leading pathogenic factor. The antigen of the SPD type was identified as Dsc-1, whereas the antigen of the IEN type is still unknown, although rare cases showed $\operatorname{IgA}$ antibodies to either Dsg-1 or Dsg-3.65${ }^{72}$ There is no clear explanation for the mechanism by which IgA autoantibodies produce characteristic skin lesions in IgA pemphigus. IgA autoantibodies might bind to the Fc receptor CD89 on monocytes and granulocytes, resulting in accumulation of neutrophils and subsequent proteolytic cleavage of the keratinocyte cell-cell junction..$^{73}$ The other issue to be considered is the possible epitopespreading phenomenon, in which an inflammatory event releases new target antigens, exposes them to the immune system, and then induces subsequent autoimmunity to new related antigens. ${ }^{74}$

\section{ASSOCIATIONS}

IgA pemphigus, particularly SPD-type, is reported to be associated with malignancies, including IgA gammopathy evolving into multiple myeloma. ${ }^{75}$ In the cases reviewed by Wallach in 1992, six of the 29 patients had an associated monoclonal gammopathy of the IgA class, with $\mathrm{k}$ light chains in five of the six patients. Two gammopathies were benign, one patient had a B-cell lymphoma, and two patients had myeloma. In two patients, the monoclonal gammopathy developed only years after the onset of the dermatosis. ${ }^{49}$ Other cases showed haematological malig-
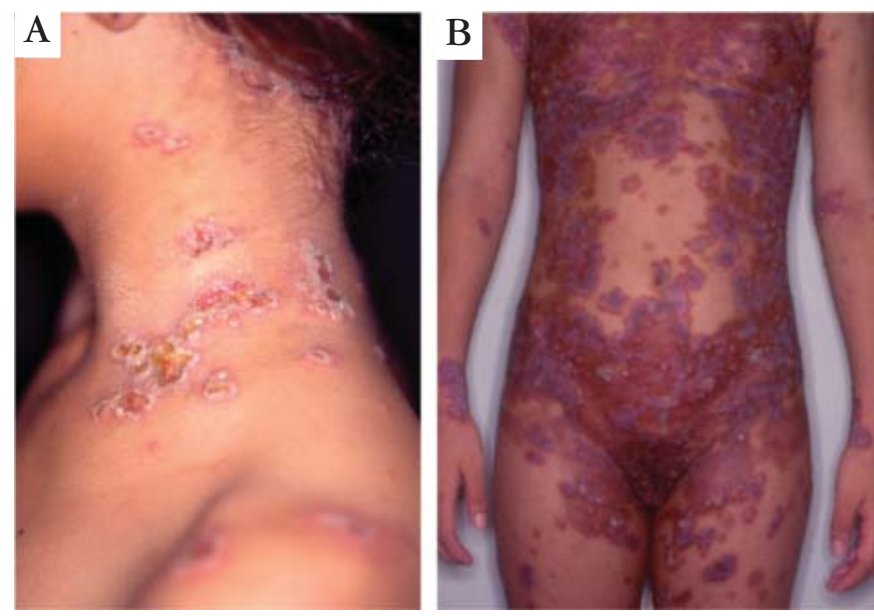
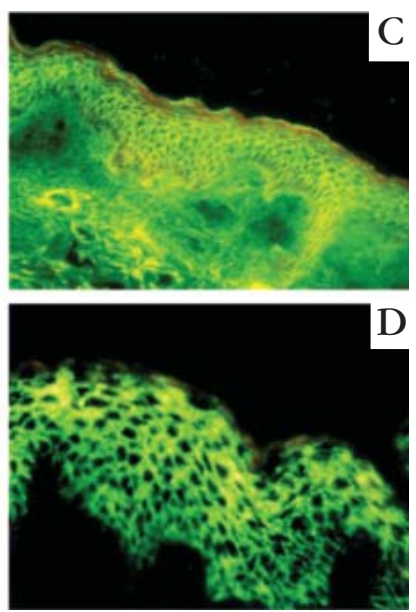

Figure 2: $\operatorname{Ig} \mathrm{A}$ Pemphigus (IEN type): (A) and (B) vesicles, blisters, pustules and crusts confluent, occupying almost the entire trunk, neck and part of the upper limbs; (C) DIF: IgA deposits intercellular;(D) IIF showing presence of $\operatorname{Ig} \mathrm{A}$ in the patient's sera (1:640) 
nancies including those of B-cell origin, while some cases were associated with solid tumours, such as lung cancer. ${ }^{76,77}$ Gastrointestinal diseases may also be associated with IgA pemphigus: one case each of Crohn's disease and gluten-sensitive enteropathy have been reported. ${ }^{49}$

\section{TREATMENT}

The small number of reported cases of IgA pemphigus disrupts the analyses of its effective treatments. The mainstays for treatment of IgA pemphigus are oral and topical corticosteroids, owing to the inflammatory nature of the disease. ${ }^{78}$ The suggested corticosteroid dose is 0.5 to $1 \mathrm{mg} / \mathrm{kg}$ daily. In addition, dapsone usually at a dose of $100 \mathrm{mg}$ daily may be very useful in treating IgA pemphigus due to its effect in suppressing neutrophilic infiltration. ${ }^{49,53,54,69,79,80}$ Isotretinoin and acitretin are also reported to be useful for the treatment of IgA pemphigus. ${ }^{81,82}$ Recently, mycophenolate mofetil and adalimumab, which are known to be effective in classic pemphigus, are also reported to be useful in treating $\operatorname{IgA}$ pemphigus. ${ }^{83}$ Colchicine was also effective in one of two patients and has also been used during the treatment of one patient (IgA pemphigus, IEN type -Figure 2) of our outpatient dermatology clinic (university hospital) with good results, together with systemic steroids. Azathioprine, a commonly-used immunosuppressant in pemphigus, does not seem to be effective in treating IgA pemphigus. ${ }^{49}$ Aggressive therapy with prednisone, cyclophosphamide and plasmapheresis has also been used for a recurrence after initial treatment with dapsone and prednisone..$^{52}$

As a superficial blistering disease, IgA pemphigus usually heals without scarring if appropriate treatment is provided. ${ }^{59,61}$ Although clinical data for its prognosis are still limited, the clinical presentation of IgA pemphigus seems to be milder and the course more benign than classic pemphigus. Recurrences of lesions have been noted after termination of treatment or reduction in drug dosage.${ }^{55}$ In those cases with an associated malignant IgA gammopathy, or other malignancies, the prognosis was related to the malignancy.

\section{PARANEOPLASTIC PEMPHIGUS}

In 1990, Anhalt et al. described five atypical pemphigus cases which were associated with lymphoproliferative disease. Anhalt called this disease paraneoplastic pemphigus (PNP). ${ }^{84}$ The term paraneoplastic autoimmune multiorgan syndrome (PAMS) was suggested later by Nguyen et al., given that is not a skin disease, but a syndrome characterized by the presence of mucocutaneous and non-cutaneous pathology associated with neoplasia..$^{85,86}$ In this article, we adopt the term PNP for historical reasons.

\section{DEFINITION AND EPIDEMIOLOGY}

In the first description by Anhalt, PNP was defined as a new mucocutaneous acantholytic disease characterized by the presence of autoantibodies (therefore named as pemphigus), in patients with neoplasia. ${ }^{84}$ These antibodies were shown to be pathogenic after inoculation in mice. ${ }^{85,87}$

The exact incidence of PNP is not known. It is a rare form of pemphigus: around 450 cases have been reported in the literature ${ }^{88}$ It predominates in men of 45 to 70 years of age ${ }^{89}$ However, case reports of the disease in children exist, and in them PNP has a predilection for those of Hispanic origin..$^{90}$ There is an association with HLA class II DRB $1 * 03$ and HLA $\mathrm{CW}^{*} 14$ in the Chinese population, different from HLAs of risk for pemphigus vulgaris and foliaceus (HLA DRB1*04 and DRB1*14). ${ }^{91,92}$

\section{CLINICAL FEATURES}

The typical initial manifestation is painful progressive stomatitis (Figures 3 and 4). ${ }^{93,94}$ Cutaneous features of PNP are polymorphic, including vesicles, blisters, erosions, patches, papules and plaques. The Nikolsky sign may be absent. ${ }^{86}$ The symptoms include the following: ${ }^{85}$ (I) pemphigus-like: superficial vesicules, flaccid blisters, erosions and crusts, occasional and limited erythema; (II) bullous pemphigoidlike: scaling erythematous papules that may be associated or not wiht tense blisters; (III) erythema multiforme-like: polymorphic lesions, mainly scaling erythematous papules with erosions or occasionally ulcers with difficult healing; (IV) graft versus host disease-like: disseminated dusky red scaly papules; (V) lichen planus-like: small squamous flat-topped violaceus papules and intense involvement of mucosal membranes (Figure 4).

PNP lesions affect not only the oral mucosa, but also esophagus, stomach, duodenum, and colon. ${ }^{95,96}$ Frequently, immunoglobulin and complement deposition in the pulmonary tissue is associated with bronchiolitis obliterans, leading to respiratory failure. ${ }^{97}$ Association of PNP with glomerulonephritis and paraneoplastic neurological syndrome has also been reported..$^{98}$

Owing to the clinical variety of PNP cases, differential diagnosis is suggested according to the predominance of the following clinical presentation: ${ }^{99}$ (I) only oral lesions: PV, oral lichen planus, major aphthous stomatitis; (II) mucositis associated to lichenoid lesions: lichen planus; (III) cutaneous and mucosal lesions: erythema multiforme, toxic epidermal necrolysis, pemphigus vulgaris.

Differentiation from PV may be difficult because of the predominance of mucosal lesions. Czernik et al..$^{86}$ indicated characteristics for distinction: 

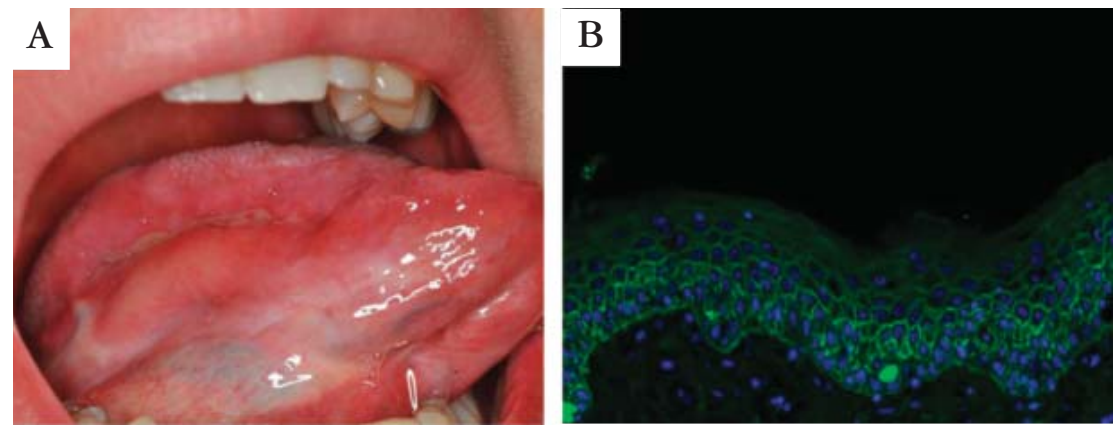

FIgURE 3: Paraneoplastic pemphigus: (A); ulcer in the side of the tongue, organ typically affected in paraneoplastic pemphigus. This patient also had erosions in the jugal mucosa and gingival enanthema. The diagnosis of an abdominal myofibroblastic tumor led to the suspicion of PNP, which was confirmed by indirect immunofluorescence in rat bladder and immunoblotting. The patient was initially treated with prednisone

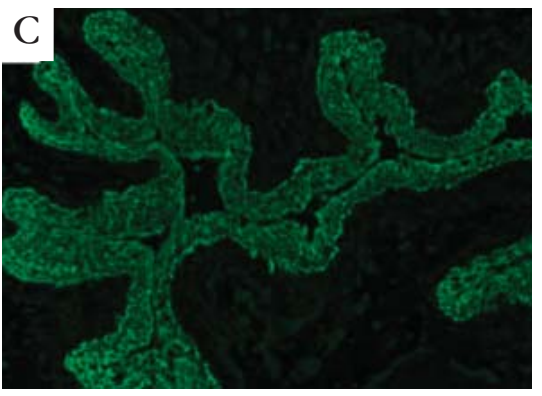

D

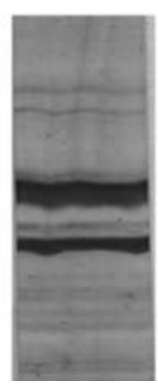

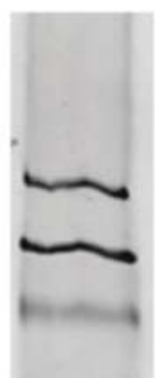
and azathioprine, and later, rituximab, with improvement; (B) DIF of perilesional patient's skin showing intercellular and basement membrane zone staining (IgG, 10x); (C) IIF in transitional epithelium: positive test for a patient with PNP (rat bladder, 10x); (D) Immunoblotting (left) and immunoprecipitation (right): detection of antibodies directed against periplakin (190 $\mathrm{kd})$ and envoplakin $(210 \mathrm{kd})$ is a criterium for diagnosis
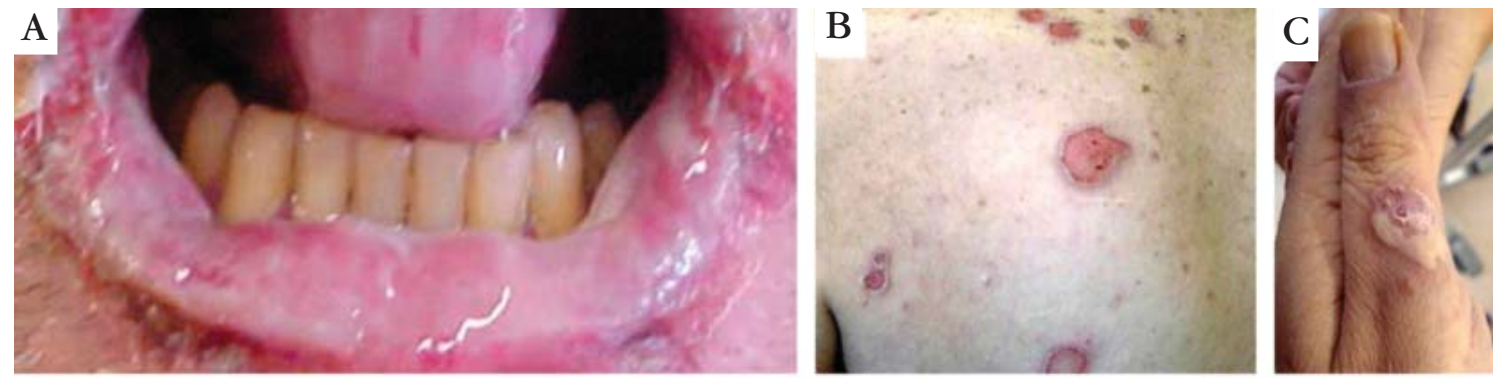

D

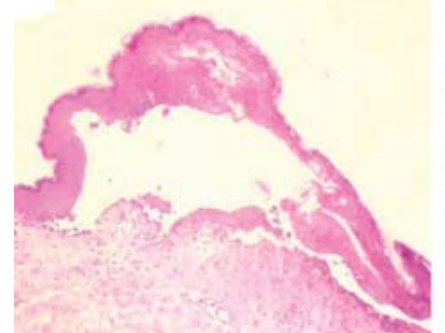

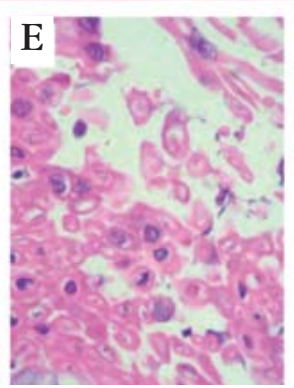
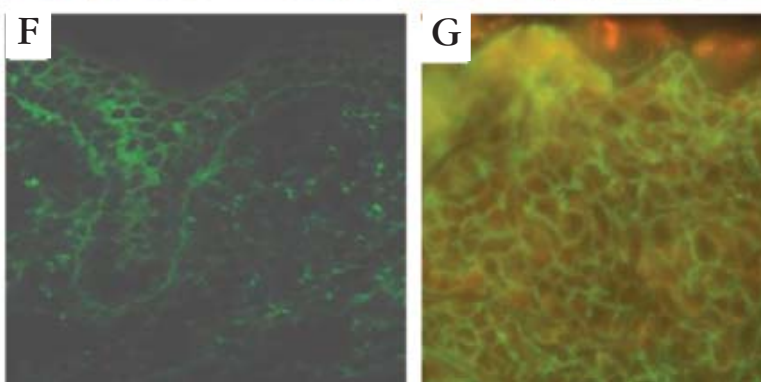

FIgURE 4: Paraneoplastic Pemphigus in patient presenting non-Hodgkin B-cell linfoma: (A) lesions affecting the lips and oral mucosa; (B) erosions on the back; (C) blisters on the hands; (D)histopathology showing suprabasal blister containing acantholytic cells (HE 40x); (E) closer view of the acantholytic cells and loss of intercellular cohesiveness (HE 400x); (F) DIF showing intercellular deposits of IgG and C3, and also linear deposits in the BMZ (DIF, 400x); (G) IIF (rat bladder) showing intercellular distribution of anti-IgG (1:320)

(I) in PV, there may be areas with healthy mucosa, while PNP is characterized by diffuse involvement of oral mucosa; (II) in PV, other mucosa such as conjunctiva are rarely involved, though involvement of other mucosa is more frequent in PNP; (III) in PV, palms and soles are spared, which generally does not occur in PNP; (IV) in PV, the scalp is frequently affected, while in PNP the scalp is spared; (V) in PV, the Nikolsky sign is present, however, this sign is absent in PNP. Mortality in PV varies between 5 and 10\% with treatment, while it is much higher in PNP, independent of therapy. ${ }^{97,100,101}$ 


\section{HISTOPATHOLOGY}

The major histopathological feature of PNP is vacuolar or lichenoid interface dermatitis pattern. ${ }^{102}$ There may be intraepidermal cleft and acantholysis, or more rarely, subepidermal blisters. ${ }^{86}$ The clinical variants also have their respective histological features: ${ }^{86}$ (I) pemphigus-like: intra-epidermal cleft surrounded by mononuclear cells; (II) bullous pemphigoid-like: subepidermal cleft with or without basal cellular vacuolization, and moderate mononuclear infiltrate in dermo-epidermal junctions; (III) erythema multiforme-like: dyskeratosis without cleft or with areas of epidermal separation, due to basal cell disintegration, and distinct perivascular infiltrate; (IV) graft versus host disease-like: absence of epidermal separation, hyperkeratosis or hyperparakeratosis and dyskeratosis with or without vacuolar degeneration of basal cell layers and intense mononuclear interface dermatitis; (V) lichen planus-like: hypergranulosis, dyskeratosis and lichenoid mononuclear infiltrate.

This range of variations in clinical and histological features is due to the different mechanisms of pathogeny in PNP: it may be a B-cell mediated disease like pemphigus or a T-cell mediated disease like lichen planus. ${ }^{85}$

\section{IMMUNOPATHOGENESIS}

Although the origin of the disease is unclear, it is speculated that the immune response in PNP may have two origins: (I) immune response to neoplastic antigens with autoantibodies that cross-react to epithelial antigens, or (II) tumors which either synthesize pathogenic autoantibodies or deregulate the immune system by synthesizing cytokines, such as IL6, which promotes B-cell differentiation and levels of which are elevated in PNP and in Castleman's disease, leading to an autoimmune response..$^{99,103}$

\section{ASSOCIATIONS}

According to the definition based on the first cases, PNP is associated with neoplasia, and rare cases are described in which neoplasia was not identified. ${ }^{84}$ Three neoplasias are commonly associated with PNP: non-Hodgkin's lymphoma (42\%), chronic lymphocytic leukemia $(29 \%)$ and Castleman's disease $(10 \%)$ (Figure 4). Other neoplasias described were thymomas (6\%), sarcomas (6\%) and Waldenstrom's macroglobulinemia (6\%). ${ }^{99}$ In children, Castleman's disease is the leading associated neoplasia..$^{90}$

\section{DIAGNOSTIC CRITERIA}

In 1990, Anhalt initially proposed five criteria for the definition of a PNP case: (1) painful mucosal erosions and polymorphous skin eruption in the context of a neoplasia; (2) histological changes (acantholysis, ker- atinocyte necrosis, interface dermatitis); (3) DIF showing IgG and complement deposition in intercellular substance and basement membrane zone; (4) IIF with the same deposition as for DIF, in skin, mucosa and simple, columnar, and transitional epithelium and (5) demonstration of serum antibodies through immunoprecipitation of a complex of four keratinocyte proteins (250, 230, 210 e $190 \mathrm{kd}$ ) (Figures 3 and 4). ${ }^{84}$

Subsequently, many authors proposed similar diagnostic criteria for PNP. ${ }^{88,99,101}$ In 2004, Anhalt proposed minimal diagnostic criteria for PNP.99 (1) clinical: painful progressive stomatitis with preferential involvement of tongue; (2) histological: acantholysis or interface dermatitis; (3) immunological: presence of antiplakin antibodies (at least periplakin and envoplakin). The pivotal criterium of PNP is autoantibodies directed against desmosomal plakin proteins: desmoplakin I (250 kDa), desmoplakin II (210 kDa), envoplakin $(210 \mathrm{kDa})$, periplakin $(190 \mathrm{kDa})$, and $\alpha 2-$ macroglobulin-like-1 protein $(170 \mathrm{kDa})$. In addition, autoantibodies against Dsg-1, Dsg-3, plectin and 230$\mathrm{kDa}$ bullous pemphigoid antigen can be detected. ${ }^{104}$ These antiplakin antibodies should be revealed by immunoprecipitation or immunoblotting, in addition to positive IIF in monkey esophagus and rat bladder (Figure 3). Anti-Dsg-3 ELISA may also be positive - but this does not discriminate between PNP and other pemphigus variants (PV and PF). (4) Association with lymphoproliferative disorder: nonHodgkin's lymphoma and chronic lymphocytic leukemia generally in cases with previous diagnosis (2/3 of cases), and Castleman's disease, abdominal lymphoma, thymomas or retroperitoneal sarcoma in cases with ocult neoplasia at the time of diagnosis of PNP (1/3 of cases). ${ }^{99}$

\section{TREATMENT}

Patients with a diagnosis of PNP without previous diagnosis of a neoplasia - about $17 \%$ of PNP cases must be investigated with complete blood count with differential leukocyte, serum protein electrophoresis, computerized tomography (chest, abdomen, and pelvis), and biopsies of bone marrow, lymph nodes, or solid tumor, according to indication. ${ }^{86,101}$

The most widely suggested specific treatment combines prednisone $(0.5-1.0 \mathrm{mg} / \mathrm{kg})$ with cyclosporine $(5 \mathrm{mg} / \mathrm{kg})$, and may also include cyclophosphamide $(2 \mathrm{mg} / \mathrm{kg})$. However, the disease is generally resistant to therapy. ${ }^{99,105}$ The mortality of patients with PNP is $75 \%$ to $90 \% .{ }^{101}$ Respiratory failure due to bronchiolitis obliterans is one of the most important causes of death in patients with PNP/PAMS ${ }^{85,97,99}$ However, a recent study, conducted in France, has made a valuable contribution to evalu- 
ating the prognosis of PNP. ${ }^{101}$ The authors analysed patients from 27 different medical centers, demonstrating that the disease course is highly variable, not only in severe cases, but also in indolent disease, and that prognosis is worst in the presence of erythema multiforme-like lesions and of necrotic keratinocytes in histopathological exam. The conclusion of this study was a mortality of $51 \%, 59 \%$ and $69 \%$ in 1, 2 and 5 years, respectively. The lower mortality than previously found might be due to the inclusion of less severe cases due to a lower threshold, since diagnosis was made if 4 of the 7 criteria were met. These 7 criteria were based on the 5 criteria of Anhalt, adding the presence of neoplasia and indirect immunofluorescence in human skin as independent criteria. ${ }^{84}$

Rituximab may be indicated, especially because of association with non-Hodgkin's lymphoma, though there are reports of complications and low therapeutic response. ${ }^{105,106}$

In general, treatment of neoplasia is not associated with improvement of PNP, except in cases associated to Castleman's disease. ${ }^{107-109}$ Tumor resection or complete response to neoplasia treatment does not alter the progression of respiratory disease, although mucocutaneous lesions may heal. ${ }^{110}$ Pulmonary disease, when present, is irreversible. ${ }^{85,86,99}$ Although the complete mechanism of bronchiolitis obliterans is not elucidated, several authors have studied the characteristics of pulmonary disease, which might contribute for future therapy. $97,11,112$

\section{IGG/ IGA PEMPHIGUS}

Over the past thirty years, some atypical and typical cases of pemphigus have been described with the name IgG/ IgA pemphigus. In most of them an intercellular pattern of IgG and IgA (and sometimes also C3) was seen in the DIF. Nishikawa et al probably were the first to report in 1987, when they described an atypical PF case during the XVII World Congress of Dermatology. ${ }^{113}$ Since then we have found another 14 similar case reports. ${ }^{114-126}$ Two other articles that studied the frequency of IgA antibodies in different bullous diseases ${ }^{127}$ and the autoantigens recognized by IgA anti-keratinocyte cell surface antibodies both describe another six not previously reported cases presenting with intercellular IgG and IgA in the DIF. ${ }^{60}$ Three other cases were also called IgG/ IgA pemphigus, despite presenting negative $\mathrm{DIF}^{128}$ or only intercellular IgG by DIF (but both intercellular IgG and IgA by IIF) or only intercellular IgA by DIF (but both intercellular IgG and IgA by IIF). ${ }^{63,29}$ Two of these cases differ from all of the others by also showing $\operatorname{IgG}^{63}$ or $\operatorname{IgG}$ and $\operatorname{IgA}$ in the BMZ by DIF. ${ }^{124}$

\section{DEFINITION AND EPIDEMIOLOGY}

There appears to be no consensus on whether this is a unique form of pemphigus. Considering the previous reports, this form could be defined as a case showing IgG and IgA intercellular deposits in the DIF studies and/or IIF, showing clinical and histologic features that can resemble PF, PV, PH or IgA pemphigus or that does not look like any of these forms (atypical). The age of the patients from the reports ranged from 11 to 81 years. A Tunisian study found only one case of IgG/ IgA pemphigus among the 92 pemphigus patients evaluated during an 11-year period. ${ }^{130}$

However a recent study brings casts doubt on whether this is really a unique entity. Mentink et al tested the sera of 100 cases of pemphigus patients (34 PF, 58 PV and 8 PNP) in both anti-Dsg- 1 and 3 IgA ELISA tests and 54 sera were found to have IgA to one or both Dsgs. ${ }^{131}$ They also found that more than half of the cases that showed IgA anti-Dsg in the ELISA presented negative staining for IgA in IIF and/or DIF. The ELISA thereby seems a more sensitive assay than IIF analysis for detecting anti-Dsg IgA antibodies. Thus they concluded that, in a considerable number of supposedly IgG mediated pemphigus patients, IgA to Dsg- 1 and Dsg-3 is also present and proposed that a spectrum with increasing IgA contribution may exist, ranging from the pure classical IgG forms via mixed IgG/IgA forms to pemphigus types with only IgA against Dsgs.

\section{CLINICAL FEATURES}

The clinical features of the reported cases are heterogeneous: PF- like, PV- like, PH-like, IgA pemphigus-like, or atypical/mixed cases. . $0,63,72,114-131$ Pruritus, pustules and annular lesions are present in almost half of the cases. Most of them do not show mucous lesions.

\section{HISTOPATHOLOGY}

The reported cases also show multiple histological features, with acantholysis in almost half of them. The level of cleavage varies from subcorneal and intraepidermal (the most common pattern) to suprabasal bulla. Neutrophilic exocytosis is present in the majority of the reports, sometimes together with eosinophils and/ or spongiosis.

\section{IMMUNO-PATHOGENESIS}

The case reports usually show $\operatorname{IgG}$ and $\operatorname{IgA}$ intercellular deposits in the DIF and/or IIF studies. Two cases deserve special note for also showing IgG or IgG and IgA in the BMZ by DIF: both presented with cutaneous and mucous lesions and subepidermal cleavage and were extensive investigated to exclude the possibility of malignancy. ${ }^{63,124}$ 
The cases are also heterogeneous concerning the target antigens: Dsg-1, Dsg-3, Dsc-1, Dsc-2, Dsc3 , and Desmoplakin 1 and 2. ${ }^{60,63,72,114-129}$

\section{ASSOCIATIONS}

The minority of cases were associated with other diseases: IgA-lambda monoclonal gammopathy, malignancy (lung cancer, ovarian carcinoma, carcinoma of the gall bladder and adenocarcinoma of the pancreas ), benign liver cyst and ovarian tumour, gastric ulcers, positive lupus anticoagulant $\operatorname{IgM}$ and increased anticardiolipin antibody and antihypertensive drug use. ${ }^{116-119,121-123,125,126}$ However, it is not clear if those are merely sporadic associations.

\section{TREATMENT}

Most of the reported cases showed good response to dapsone, with or without systemic corticosteroids or to topical or systemic steroids alone. Other immunosuppressant drugs were required only in one case. Other drugs employed were acitretin, antimalarial and nicotinamide and minocycline. .11, $22,123,124^{12}$

\section{CONCLUSION}

This article has reviewed the knowledge about the nonclassical forms of pemphigus. Future research on the patho-physiology and the role of the target antigens may help to answer some questions that are still not clear, especially concerning the proper position of pemphigus herpetiformis and IgG/ IgA pemphigus in the pemphigus group.

\section{ACKNOWLEDGEMENTS}

The authors would like to thank the patients the major reason for writing this review; the contributions of Prof. Dr. Marcel F. Jonkman and Angelique Poot, MD, from the Center for Blistering Diseases, Groningen University Medical Center, University of Groningen in the Netherlands, for reviewing the English manuscript and for iconographic contribution on PNP; and Mrs. Diane Black, from the Language Center, University of Groningen, the Netherlands, for her final contribution to the English manuscript (PNP).

\section{REFERENCES}

1. Patrício P, Ferreira C, Gomes MM, Filipe P. Autoimmune bullous dermatoses: a review. Ann N Y Acad Sci. 2009 Sep;1173:203-10

2. Amagai M, Hashimoto T, Green KJ, Shimizu N, Nishikawa T. Antigen-specific immunoadsorption of pathogenic autoantibodies in pemphigus foliaceus. J Invest Dermatol. 1995;104:895-901.

3. Amagai M, Klaus-Kovtun V, Stanley JR. Autoantibodies against a novel epithelia cadherin in pemphigus vulgaris, a disease of cell adhesion. Cell. 1991;67:869-77.

4. Robinson ND, Hashimoto T, Amagai M, Chan LS. The new pemphigus variants. J Am Acad Dermatol. 1999;40:649-71

5. Floden $\mathrm{CH}$, Centale $\mathrm{H}$. A case of clinically typical dermatitis herpetiformis ( $\mathrm{M}$. Duhring) presenting acantholysis. Acta Derm Venereol. 1955;35:128-31.

6. Sneddon I, Church R. Pemphigus foliaceous presenting as dermatitis herpetiformis. Acta Derm Venereol. 1967;47:440-6.

7. Emmerson RW, Wilson-Jones E. Eosinophilic spongiosis in pemphigus. A report of unusual histological change in pemphigus. Arch Dermatol. 1968;97:252-7.

8. DeMento FJ, Grover RW. Acantholytic herpetiform dermatitis. Arch Dermatol. 1973;107:883-7.

9. Seah PP, Fry L, Cairns RJ, Feiwel M. Pemphigus controlled by sulphapyridine. Br J Dermatol. 1973;89:77-81.

10. Barrance VP. Mixed bullous disease. Arch Dermatol. 1974;110:221-4

11. Jablonska S, Chorzelski TP, Beutner EH, Chorzelska J. Herpetiform pemphigus, a variable pattern of pemphigus. Int J Dermatol. 1975;14:353-9.

12. Maciejowska $\mathrm{E}$, Jablonska $\mathrm{S}$, Chorzelski T. Is pemphigus herpetiformis an entity? Int J Dermatol. 1987;26:571-7.

13. Santi CG, Maruta CW, Aoki V, Sotto MN, Rivitti EA, Diaz LA. Pemphigus herpetiformis is a rare clinical expression of nonendemic pemphigus foliaceus, fogo selvagem, and pemphigus vulgaris. Cooperative Group on Fogo Selvagem Research. J Am Acad Dermatol. 1996;34:40-6.

14. Verdier-Sevrain S, Joly P, Thomine E, Belanyi P, Gilbert D, Tron F, et al.Thiopronineinduced herpetiform pemphigus: report of a case studied by immunoelectron microscopy and immunoblot analysis. Br J Dermatol. 1994;130:238-40.

15. Ishii K, Amagai M, Komai A, Ebihara T, Chorzelski TP, Jablonska S, et al. Desmoglein 1 and desmoglein 3 are the target autoantigens in herpetiform pemphigus. Arch Dermatol. 1999;135:943-7.

16. Kubo A, Amagai M, Hashimoto T, Doi T, Higashiyama M, Hashimoto K, et al. Herpetiform pemphigus showing reactivity with pemphigus vulgaris antigen (desmoglein 3). Br J Dermatol. 1997;137:109-13.
17. Miyagawa S, Amagai M, lida T, Yamamoto Y, Nishikawa T, Shirai T. Late development of antidesmoglein 1 antibodies in pemphigus vulgaris: correlation with disease progression. Br J Dermatol. 1999;141:1084-7.

18. Tateishi C, Tsuruta D, Nakanishi T, Uehara S, Kobayashi H, Ishii M,, et al. Antidesmocollin-1 antibody-positive, antidesmoglein antibody-negative pemphigus herpetiformis. J Am Acad Dermatol. 2010;63:e8-10.

19. Ohata C, Koga H, Teye K, Ishii N, Hamada T, Dainichi T, et al. Concurrence of bullous pemphigoid and herpetiform pemphigus with IgG antibodies to desmogleins 1/3 and desmocollins 1-3. Br J Dermatol. 2013;168:879-81.

20. Prado R, Brice SL, Fukuda S, Hashimoto T, Fujita M. Paraneoplastic pemphigus herpetiformis with $\lg \mathrm{G}$ antibodies to desmoglein 3 and without mucosal lesions. Arch Dermatol. 2011;147:67-71.

21. Kitajima Y, Aoyama Y. A perspective of pemphigus from bedside and laboratorybench. Clin Rev Allergy Immunol. 2007;33:57-66.

22. Marzano AV, Tourlaki A, Cozzani E, Gianotti R, Caputo R. Pemphigus herpetiformis associated with prostate cancer. J Eur Acad Dermatol Venereol. 2007;21:696-8.

23. Lu Y, Zhang M. Pemphigus herpetiformis in a patient with well-differentiated cutaneous angiosarcoma: case report and review of the published work. J Dermatol. 2012;39:89-91.

24. Durham A, Carlos CA, Gudjonsson JE, Lowe L, Hristov AC. Pemphigus herpetiformis: Report of a rare case. J Am Acad Dermatol. 2012;67:e231-3.

25. Ohyama B, Nishifuji K, Chan PT, Kawaguchi A, Yamashita T, Ishii N, et al. Epitope spreading is rarely found in pemphigus vulgaris by large-scale longitudinal study using desmoglein 2-based swapped molecules. J Invest Dermatol. 2012;132:1158-68.

26. Miura T, Kawakami Y, Oyama N, Ohtsuka M, Suzuki Y, Ohyama B, et al. A case of pemphigus herpetiformis with absence of antibodies to desmogleins 1 and 3. J Eur Acad Dermatol Venereol. 2010;24:101-3.

27. Hashimoto T. Recent advances in the study of the pathophysiology of pemphigus. Arch Dermatol Res. 2003;295:S2-11.

28. Micali G, Musumeci ML, Nasca MR. Epidemiologic analysis and clinical course of 84 consecutive cases of pemphigus in eastern Sicily. Int J Dermatol. 1998;37:197200.

29. Leithauser LA, Mutasim DF. A Case of Pemphigus Herpetiformis Occurring in a 9Year-Old Boy. Pediatr Dermatol. 2012 [Epub ahead of print]

30. Moutran R, Maatouk I, Stephan F, Halaby E, Abadjian G, Tomb R. Letter: Pemphigus herpetiformis of age of onset at 6 years. Dermatol Online J. 2011;17:10. 
31. Duarte IB, Bastazini I Jr, Barreto JA, Carvalho CV, Nunes AJ. Pemphigus herpetiformis in childhood. Pediatr Dermatol. 2010;27:488-91.

32. Ingber A, Feuerman EJ. Pemphigus with characteristics of dermatitis herpetiformis A long-term follow-up of five patients. Int J Dermatol. 1986;25:575-9.

33. Cunha PR, Jiao D, Bystryn JC. Simultaneous occurrence of herpetiform pemphigus and endemic pemphigus foliaceus (fogo selvagem). Int $\mathrm{J}$ Dermatol. 1997:36:850-4.

34. Fernandes IC, Sanches M, Alves R, Selores M. Case for diagnosis. Bullous eruption with herpetiform pattern. An Bras Dermatol. 2012;87:933-5.

35. Huhn KM, Tron VA, Nguyen N, Trotter MJ. Neutrophilic spongiosis in pemphigus herpetiformis. J Cutan Pathol. 1996;23:264-9.

36. Amagai M. Autoimmunity against desmosomal cadherins in pemphigus. $J$ Dermatol Sci. 1999;20:92-102.

37. O'Toole EA, Mak LL, Guitart J, Woodley DT, Hashimoto T, Amagai M, et al. Induction of keratinocyte IL-8 expression and secretion by lgG autoantibodies as a novel mechanism of epidermal neutrophil recruitment in a pemphigus variant. Clin Exp Immunol. 2000;119:217-24.

38. Morita E, Amagai M, Tanaka T, Horiuchi K, Yamamoto S. A case of herpetiform pemphigus coexisting with psoriasis vulgaris. Br J Dermatol. 1999;141:754-5.

39. Sanchez-Palacios C, Chan LS. Development of pemphigus herpetiformis in a patient with psoriasis receiving UV-light treatment. J Cutan Pathol. 2004;31:346-9.

40. Lebeau S, Müller R, Masouyé I, Hertl M, Borradori L. Pemphigus herpetiformis: analysis of the autoantibody profile during the disease course with changes in the clinical phenotype. Clin Exp Dermatol. 2010;35:366-72.

41. Marinović B, Basta-Juzbasić A, Bukvić-Mokos Z, Leović R, Loncarić D. Coexistence of pemphigus herpetiformis and systemic lupus erythematosus. J Eur Acad Dermatol Venereol. 2003;17:316-9.

42. Bull RH, Fallowfield ME, Marsden RA. Autoimmune blistering diseases associated with HIV infection. Clin Exp Dermatol. 1994;19:47-50.

43. Kubota Y, Yoshino Y, Mizoguchi M. A case of herpetiform pemphigus associated with lung câncer. J Dermatol. 1994;21:609-11.

44. Palleschi GM, Giomi B. Herpetiformis pemphigus and lung carcinoma: a case of paraneoplastic pemphigus. Acta Derm Venereol. 2002;82:304-5.

45. Nakashima H, Fujimoto M, Watanabe R, Ishiura N, Yamamoto Al, Hashimoto $\mathrm{T}$, et al. Herpetiform pemphigus without anti-desmoglein $1 / 3$ autoantibodies. J Dermatol. 2010;;37:264-8.

46. Arranz D, Corral M, Prats I, López-Ayala E, Castillo C, Vidaurrázaga C, et al. Herpetiform pemphigus associated with esophageal carcinoma. Actas Dermosifiliogr. 2005;96:119-21.

47. Wallach D, Foldès $\mathrm{C}$, Cottenot $\mathrm{F}$. Pustulose sous-cornee,acantholyse superficielle et IgA monoclonale. Ann Dermatol Venereol. 1982;109:959-63.

48. Hashimoto T. Immunopathology of IgA pemphigus. Clin Dermatol. 2001;19:683-9.

49. Wallach D. Intraepidermal IgA pustulosis. J Am Acad Dermatol. 1992;7:993-1000.

50. Gengoux P, Tennstedt D, Lachapelle JM. Intraepidermal neutrophilic IgA dermatosis: pemphigus-like IgA deposits. Dermatology. 1992;185:311-3.

51. Hashimoto T, Ebihara T, Dmochowski M, Kawamura K, Suzuki T, Tsurufuji S, et al. IgA antikeratinocyte surface autoantibodies from two types of intercellular IgA vesiculopustular dermatosis recognize distinct isoforms of desmocollin. Arch Dermatol Res. 1996;288:447-52.

52. Chorzelski TP, Beutner EH, Kowalewski C, Olszewska M, Maciejowska E, Seferowicz E, et al. IgA pemphigus foliaceus with a clinical presentation of pemphigus herpetiformis. J Am Acad Dermatol. 1991;24:839-44.

53. Beutner EH, Chorzelski TP, Wilson RM, Kumar V, Michel B, Helm F, et al. IgA pemphigus foliaceus: report of two cases and a review of the literature. J Am Acad Dermatol. 1989;20:89-97.

54. Huff JC, Golitz LE, Kunke KS. Intraepidermal neutrophilic IgA dermatosis. N Engl J Med. 1985;313:1643-5.

55. Hashimoto T, Inamoto N, Nakamura K, Nishikawa T. Intercellular IgA dermatosis with clinical features of subcorneal pustular dermatosis. Arch Dermatol. 1987;123:1062-5

56. Tagami H, Iwatsuki K, Iwase $\mathrm{Y}$, Yamada M. Subcorneal pustular dermatosis with vesiculo-bullous eruption: demonstration of subcorneal IgA deposits and a leukocyte chemotactic factor. Br J Dermatol. 1983;109:581-7.

57. Hodak E, David M, Ingber A, Rotem A, Hazaz B, Shamai-Lubovitz O, et al. The clinical and histopathological spectrum of IgA-pemphigus: report of two cases. Clin Exp Dermatol. 1990;15:433-7.

58. Tajima M, Mitsuhashi Y, Irisawa R, Amagai M, Hashimoto T, Tsuboi R.. IgA pemphigus reacting exclusively to desmoglein 3. Eur J Dermatol. 2010;20:626-9.

59. E-medicine. medscape.com [homepage on the Internet]. Chan LS. IgA Pemphigus. [cited 2010 Apr 9]. Available from: http://www.emedicine.medscape.com/article/1063776-overview.

60. Hashimoto T, Ebihara T, Nishikawa T. Studies of autoantigens recognized by $\lg A$ anti-keratinocyte cell surface antibodies. J Dermatol Sci. 1996;12:10-7.
61. Wang J, Kwon J, Ding X, Fairley JA, Woodley DT, Chan LS. Nonsecretory IgA1 autoantibodies targeting desmosomal component desmoglein 3 in intraepidermal neutrophilic IgA dermatosis. Am J Pathol. 1997;150:1901-7.

62. Lutz ME, Daoud MS, McEvoy MT, Gibson LE. Subcorneal pustular dermatosis: a clinical study of ten patients. Cutis. 1998;61:203-8.

63. Bruckner AL, Fitzpatrick JE, Hashimoto T, Weston WL, Morelli JG. Atypical lgA/ IgG pemphigus involving the skin, oral mucosa, and colon in a child: a novel variant of IgA pemphigus? Pediatr Dermatol. 2005;22:321-7.

64. Hashimoto T, Komai A, Futei Y, Nishikawa T, Amagai M. Detection of IgA autoantibodies to desmogleins by an enzyme-linked immunosorbent assay: the presence of new minor subtypes of IgA pemphigus. Arch Dermatol. 2001;137:735-8.

65. Amagai M. Adhesion molecules I: Keratinocyte-keratinocyte interactions; cadherins and pemphigus. J Invest Dermatol. 1995;104:146-52.

66. Buxton RS, Cowin P, Franke WW, Garrod DR, Green KJ, King IA, et al. Nomenclature of the desmosomal cadherins. J Cell Biol. 1993;121:481-3.

67. Hashimoto T, Kiyokawa C, Mori O, Miyasato M, Chidgey MA, Garrod DR, et al. Human desmocollin 1(Dsc1) is an autoantigen for subcorneal pustular dermatosis type of IgA pemphigus. J Invest Dermatol. 1997;109:127-31.

68. Ishii N, Ishida-Yamamoto A, Hashimoto T. Immunolocalization of target autoantigens in IgA pemphigus. Clin Exp Dermatol. 2004;29:62-6.

69. Yasuda H, Kobayashi H, Hashimoto T, Itoh K, Yamane M, Nakamura J. Subcorneal pustular dermatosis type of IgA pemphigus: demonstration of autoantibodies to desmocollin-1 and clinical review. Br J Dermatol. 2000;143:144-8.

70. Kopp T, Sitaru C, Pieczkowski F, Schneeberger A, Födinger D, Zillikens D, et al. IgA pemphigus-occurrence of anti-desmocollin 1 and anti-desmoglein 1 antibody reactivity in an individual patient. J Dtsch Dermatol Ges. 2006;4(:1045-50.

71. Düker I, Schaller J, Rose C, Zillikens D, Hashimoto T, Kunze J. Subcorneal pustular dermatosis-type IgA pemphigus with autoantibodies to desmocollins 1, 2, and 3. Arch Dermatol. 2009;145:1159-62.

72. Zaraa I, Kerkeni N, Sellami M, Chelly I, Zitouna M, Makni S, Mokni M, et al. IgG/lgA pemphigus with $\lg G$ and $\lg A$ antidesmoglein 3 antibodies and IgA antidesmoglein 1 antibodies detected by enzyme-linked immunosorbent assay: a case report and review of the literature. Int J Dermatol. 2010;49:298-302.

73. Tsuruta D, Ishii N, Hamada T, Ohyama B, Fukuda S, Koga H, et al. IgA pemphigus. Clin Dermatol. 2011;29:437-42.

74. Chan LS, Vanderlugt CJ, Hashimoto T, Nishikawa T, Zone JJ, Black MM, et al. Epitope spreading: lessons from autoimmune skindiseases. J Invest Dermatol. 1998:110:103-9

75. Szturz P, Adam Z, Klincová M, Feit J, Krejčí M, Pour L, et al. Multiple myeloma associated IgA pemphigus: treatment with bortezomib- and lenalidomidebased regimen. Clin Lymphoma Myeloma Leuk. 2011;11:517-20.

76. Taintor AR, Leiferman KM, Hashimoto T, Ishii N, Zone JJ, Hull CM, et al. A novel case of IgA paraneoplastic pemphigus associated with chronic lymphocytic leukemia. J Am Acad Dermatol. 2007;56:S73-6.

77. Asahina A, Koga H, Suzuki Y, Hashimoto T. IgA pemphigus associated with diffuse large B-cell lymphoma showing unique reactivity histopathological features. $\mathrm{Br} \mathrm{J}$ Dermatol. 2013;168:224-6.

78. Camisa C, Warner M. Treatment of pemphigus. Dermatol Nurs. 1998;10:115-8, 123-31.

79. Sneddon IB, Wilkinson DS. Subcorneal pustular dermatosis. Br J Dermatol. 1979;100:61-8.

80. Weston WL, Friednash M, Hashimoto T, Seline P, Huff JC, Morelli JG. A novel childhood pemphigus vegetans variant of intraepidermal neutrophilic IgA dermatosis. J Am Acad Dermatol. 1998;38:635-8.

81. Gruss C, Zillikens D, Hashimoto T, Amagai M, Kroiss M, Vogt T, et al. Rapid response of IgA pemphigus of subcorneal pustular dermatosis type to treatment with isotretinoin. J Am Acad Dermatol. 2000;43:923-6.

82. Ruiz-Genao DP, Hernández-Núñez A, Hashimoto $\mathrm{T}$, Amagai M, Fernández-Herrera J, García-Díez A. A case of IgA pemphigus successfully treated with acitretin. $\mathrm{Br} J$ Dermatol. 2002;147:1040-2.

83. Howell SM, Bessinger GT, Altman CE, Belnap CM. Rapid response of IgA pemphigus of the subcorneal pustular dermatosis subtype to treatment with adalimumab and mycophenolate mofetil. J Am Acad Dermatol. 2005 Sep;53(3):541-3.

84. Anhalt GJ, Kim SC, Stanley JR, Korman NJ, Jabs DA, Kory M, et al. Paraneoplastic pemphigus. An autoimmune mucocutaneous disease associated with neoplasia. N Engl J Med. 1990;323:1729-35.

85. Nguyen VT, Ndoye A, Bassler KD, Shultz LD, Shields MC, Ruben BS, et al. Classification, clinical manifestations, and immunopathological mechanisms of the epithelial variant of paraneoplastic autoimmune multiorgan syndrome: a reappraisal of paraneoplastic pemphigus. Arch Dermatol. 2001;137:193-206.

86. Czernik A, Camilleri M, Pittelkow MR, Grando SA. Paraneoplastic autoimmune multiorgan syndrome: 20 years after. Int J Dermatol. 2011;50:905-14. 
87. Amagai M, Nishikawa T, Nousari HC, Anhalt GJ, Hashimoto T. Antibodies against desmoglein 3 (pemphigus vulgaris antigen) are present in sera from patients with paraneoplastic pemphigus and cause acantholysis in vivo in neonatal mice. J Clin Invest. 1998;102:775-82.

88. Zimmermann J, Bahmer F, Rose C, Zillikens D, Schmidt E. Clinical and immunopathological spectrum of paraneoplastic pemphigus. J Dtsch Dermatol Ges. 2010:8:598-606

89. Kimyai-Asadi A, Jih MH. Paraneoplastic pemphigus. Int J Dermatol. 2001;40:367-72.

90. Mimouni D, Anhalt GJ, Lazarova Z, Aho S, Kazerounian S, Kouba DJ, et al. Paraneoplastic pemphigus in children and adolescents. $\mathrm{Br} \mathrm{J}$ Dermatol. 2002;147:725-32.

91. Martel P, Loiseau P, Joly P, Busson M, Lepage V, Mouquet $\mathrm{H}$, et al. Paraneoplastic pemphigus is associated with the DRB1*03 allele. J Autoimmun. 2003;20:91-5.

92. Liu Q, Bu DF, Li D, Zhu XJ. Genotyping of HLA-I and HLA-II alleles in Chinese patients with paraneoplastic pemphigus. Br J Dermatol. 2008;158:587-91.

93. Kaplan I, Hodak E, Ackerman L, Mimouni D, Anhalt GJ, Calderon S. Neoplasms associated with paraneoplastic pemphigus: a review with emphasis on non-hematologic malignancy and oral mucosal manifestations. Oral Oncol. 2004;40:553-62.

94. Sklavounou A, Laskaris G. Paraneoplastic pemphigus: a review. Oral Oncol. 1998;34:437-40.

95. Wakahara M, Kiyohara T, Kumakiri M, Ueda T, Ishiguro K, Fujita T, et al. Paraneoplastic pemphigus with widespread mucosal involvement. Acta Derm Venereol. 2005;85:530-2.

96. Miida H, Kazama T, Inomata N, Takizawa H, Iwafuchi M, Ito M, et al. Severe gastrointestinal involvement in paraneoplastic pemphigus. Eur J Dermatol. 2006;16(4):420-2.

97. Nousari HC, Deterding R, Wojtczack H, Aho S, Uitto J, Hashimoto T, et al. The mechanism of respiratory failure in paraneoplastic pemphigus. N Engl $\mathrm{J}$ Med. 1999;340:1406-10.

98. Qian SX, Li JY, Hong M, Xu W, Qiu HX. Nonhematological autoimmunity (glomeruIosclerosis, paraneoplastic pemphigus and paraneoplastic neurological syndrome) in a patient with chronic lymphocytic leukemia: Diagnosis, prognosis and management. Leuk Res. 2009:33:500-5

99. Anhalt GJ. Paraneoplastic pemphigus. J Investig Dermatol Symp Proc. 2004;9:29-33.

100. Mimouni D, Bar H, Gdalevich M, Katzenelson V, David M. Pemphigus, analysis of 155 patients. J Eur Acad Dermatol Venereol. 2010;24:947-52.

101. Leger S, Picard D, Ingen-Housz-Oro S, Arnault JP, Aubin F, Carsuzaa F, et al. Prognostic factors of paraneoplastic pemphigus. Arch Dermatol. 2012;148:1165-72.

102. Horn TD, Anhalt GJ. Histologic features of paraneoplastic pemphigus. Arch Dermatol. 1992:128:1091-5

103. Nousari HC, Kimyai-Asadi A, Anhalt GJ. Elevated serum levels of interleukin-6 in paraneoplastic pemphigus. J Invest Dermatol. 1999;112:396-8.

104. Schepens I, Jaunin F, Begre N, Läderach U, Marcus K, Hashimoto T, et al. The protease inhibitor alpha-2-macroglobulin-like-1 is the p170 antigen recognized by paraneoplastic pemphigus autoantibodies in human. PLoS One. 2010;5:e12250.

105. Borradori L, Lombardi T, Samson J, Girardet C, Saurat JH, Hügli A. Anti-CD20 monoclonal antibody (rituximab) for refractory erosive stomatitis secondary to CD20(+) follicular lymphoma-associated paraneoplastic pemphigus. Arch Dermatol. 2001;137:269-72.

106. Hertl M, Zillikens D, Borradori L, Bruckner-Tuderman L, Burckhard H, Eming R, et al. Recommendations for the use of rituximab (anti-CD20 antibody) in the treatment of autoimmune bullous skin diseases. J Dtsch Dermatol Ges. 2008;6:366-73.

107. Fang Y, Zhao L, Yan F, Cui X, Xia Y, Duren A. A critical role of surgery in the treatment for paraneoplastic pemphigus caused by localized Castleman's disease. Med Oncol. 2010;27:907-11.

108. Wang J, Zhu X, Li R, Tu P, Wang R, Zhang L, et al. Paraneoplastic pemphigus associated with Castleman tumor: a commonly reported subtype of paraneoplastic pemphigus in China. Arch Dermatol. 2005;141:1285-93.

109. Zhu X, Zhang B. Paraneoplastic pemphigus. J Dermatol. 2007;34:503-11.

110. Maldonado F, Pittelkow MR, Ryu JH. Constrictive bronchiolitis associated with paraneoplastic autoimmune multi-organ syndrome. Respirology. 2009 ;14:129-33.

111. lida K, Yamaguchi F, Hibi K, Tate G, Ohyama B, Numata S, et al. Characterization of inflammatory infiltrates in lesions of the oral mucosa, skin, and bronchioles in a case of paraneoplastic pemphigus. Eur J Dermatol. 2012;22:154-5.

112. Fullerton SH, Woodley DT, Smoller BR, Anhalt GJ. Paraneoplastic pemphigus with autoantibody deposition in bronchial epithelium after autologous bone marrow transplantation. JAMA. 1992;267:1500-2.

113. Nishikawa T, Shimizu H, Hashimoto T. Role of IgA intercellular antibodies: report of clinically and immunopathologically atypical cases. Proceedings of the XVII. World Congress Dermatol. 1987;383-384.
114. Hosoda S, Suzuki M, Komine M, Murata S, Hashimoto T, Ohtsuki M. A case of $\lg \mathrm{G} / \mathrm{IgA}$ pemphigus presenting malar rash-like erythema. Acta Derm Venereol. 2012:92:164-6

115. Feng SY, Zhi L, Jin PY, Zhou WQ, Yin YP. A case of $\lg A / \lg G$ pustular pemphigus. Int J Dermatol. 2012;51:321-4.

116. Santiago-et-Sánchez-Mateos D, Juárez Martín A, González De Arriba A, Delgado Jiménez $Y$, Fraga J, Hashimoto $T$, et al. $\lg G / \lg A$ pemphigus with $\lg A$ and $\lg G$ antidesmoglein 1 antibodies detected by enzyme-linked immunosorbent assay: presentation of two cases. J Eur Acad Dermatol Venereol. 2011;25:110-2.

117. Maruyama H, Kawachi $Y$, Fujisawa $Y$, Itoh S, Furuta J, Ishii $Y$, et al. IgA/lgG pemphigus positive for anti-desmoglein 1 autoantibody. Eur J Dermatol. 2007;17:94-5.

118. Kowalewski C, Hashimoto T, Amagai M, Jablonska S, Mackiewicz W, Wozniak K. IgA/lgG pemphigus: a new atypical subset of pemphigus? Acta Derm Venereol. 2006;86:357-8

119. Inui S, Amagai M, Tsutsui S, Fukuhara-Yoshida S, Itami S, Katayama I. Atypical pemphigus involving the esophagus with IgG antibodies to desmoglein 3 and $\lg A$ antibodies to desmoglein 1. J Am Acad Dermatol. 2006;55:354-5.

120. Heng A, Nwaneshiudu A, Hashimoto T, Amagai M, Stanley JR. Intraepidermal neutrophilic IgA/lgG antidesmocollin 1 pemphigus. Br J Dermatol. 2006;154:1018-20.

121. Morizane S, Yamamoto T, Hisamatsu Y, Tsuji K, Oono T, Hashimoto T, et al Pemphigus vegetans with $\lg \mathrm{G}$ and $\lg \mathrm{A}$ antidesmoglein 3 antibodies. $\mathrm{Br} \mathrm{J}$ Dermatol. 2005;153:1236-7

122. Kozlowska A, Hashimoto T, Jarzabek-Chorzelska M, Amagai A, Nagata $Y$, Strasz Z, et al. Pemphigus herpetiformis with $\lg A$ and $\lg G$ antibodies to desmoglein 1 and IgG antibodies to desmocollin 3. J Am Acad Dermatol. 2003;48:117-22.

123. Oiso N, Yamashita C, Yoshioka K, Amagai M, Komai A, Nagata Y, et al. IgG/lgA pemphigus with $\lg \mathrm{G}$ and $\lg \mathrm{A}$ antidesmoglein 1 antibodies detected by enzyme-linked immunosorbent assay. Br J Dermatol. 2002;147:1012-7.

124. Gooptu C, Mendelsohn S, Amagai M, Hashimoto T, Nishikawa T, Wojnarowska F. Unique immunobullous disease in a child with a predominantly $\lg A$ response to three desmosal protein. Br J Dermatol. 1999;141:882-6.

125. Miyagawa S, Hashimoto T, Ohno H, Nakagawa A, Watanabe K, Nishikawa T, et al. Atypical pemphigus associated with monoclonal IgA gammopathy. J Am Acad Dermatol. 1995;32:352-7.

126. Chorzelski TP, Hashimoto T, Nishikawa T, Ebihara T, Dmochowski M, Ismail M, et al. Unusual acantholytic bullous dermatosis associated with neoplasia and IgG and IgA antibodies against bovine desmocollins I and II. J Am Acad Dermatol. 1994;31:351-5

127. Cozzani E, Drosera M, Parodi A, Carrozzo M, Gandolfo S, Rebora A. Frequency of $\lg A$ antibodies in pemphigus, bullous pemphigoid and mucous membrane pemphigoid. Acta Derm Venereol. 2004;84:381-4.

128. Müller R, Heber B, Hashimoto T, Messer G, Müllegger R, Niedermeier A, et al. Autoantibodies against desmocollins in European patients with pemphigus. Clin Exp Dermatol. 2009;34:898-903.

129. Nakajima K, Hashimoto T, Nakajima H, Yokogawa M, Ikeda M, Kodama H. IgG/lgA pemphigus with dyskeratotic acantholysis and intraepidermal neutrophilic microabscesses. J Dermatol. 2007:34:757-60.

130. Zaraa I, Kerkeni N, Ishak F, Zribi H, El Euch D, Mokni M, et al. Spectrum of autoimmune blistering dermatoses in Tunisia: an 11-year study and a review of the literature. Int J Dermatol. 2011;50:939-44.

131. Mentink LF, de Jong MC, Kloosterhuis GJ, Zuiderveen J, Jonkman MF, Pas HH Coexistence of $\lg A$ antibodies to desmogleins 1 and 3 in pemphigus vulgaris, pemphigus foliaceus and paraneoplastic pemphigus. $\mathrm{Br} \mathrm{J}$ Dermatol. 2007;156:635-41.

How to cite this article: Porro AM, Caetano L de VN, Maehara L de SN, Enokihara MMS. Non-classical forms of pemphigus: pemphigus herpetiformis, IgA pemphigus, paraneoplastic pemphigus and IgG/IgA pemphigus. An Bras Dermatol. 2014;89(1):96-117.

\author{
MAILING ADDRESS: \\ Adriana Maria Porro \\ Rua Borges Lagoa 508 - Vila Clementino \\ São Paulo - SP \\ Brazil \\ E-mail:adriana.porro@uol.com.br
}

